\title{
Conceptual Process Design and Techno-Economic Assessment of Ex Situ Catalytic Fast Pyrolysis of Biomass: A Fixed Bed Reactor Implementation Scenario for Future Feasibility
}

\author{
Abhijit Dutta $^{1}$ - Joshua A. Schaidle ${ }^{1}$ David Humbird ${ }^{2} \cdot$ Frederick G. Baddour $^{3}$ • \\ Asad Sahir ${ }^{1}$
}

Published online: 6 October 2015

(C) The Author(s) 2015. This article is published with open access at Springerlink.com

\begin{abstract}
Ex situ catalytic fast pyrolysis of biomass is a promising route for the production of fungible liquid biofuels. There is significant ongoing research on the design and development of catalysts for this process. However, there are a limited number of studies investigating process configurations and their effects on biorefinery economics. Herein we present a conceptual process design with techno-economic assessment; it includes the production of upgraded bio-oil via fixed bed ex situ catalytic fast pyrolysis followed by final hydroprocessing to hydrocarbon fuel blendstocks. This study builds upon previous work using fluidized bed systems, as detailed in a recent design report led by the National Renewable Energy Laboratory (NREL/ TP-5100-62455); overall yields are assumed to be similar, and are based on enabling future feasibility. Assuming similar yields provides a basis for easy comparison and for studying the impacts of areas of focus in this study, namely, fixed bed reactor configurations and their catalyst development requirements, and the impacts of an inline hot gas filter. A comparison with the fluidized bed system
\end{abstract}

Electronic supplementary material The online version of this article (doi:10.1007/s11244-015-0500-z) contains supplementary material, which is available to authorized users.

\section{Abhijit Dutta}

Abhijit.Dutta@nrel.gov

$\triangle$ Joshua A. Schaidle

Joshua.Schaidle@nrel.gov

1 National Bioenergy Center, National Renewable Energy Laboratory, 15013 Denver West Parkway, Golden, CO, USA

2 DWH Process Consulting, Centennial, CO, USA

3 Chemistry and Nanoscience Center, National Renewable Energy Laboratory, 15013 Denver West Parkway, Golden, CO, USA shows that there is potential for higher capital costs and lower catalyst costs in the fixed bed system, leading to comparable overall costs. The key catalyst requirement is to enable the effective transformation of highly oxygenated biomass into hydrocarbons products with properties suitable for blending into current fuels. Potential catalyst materials are discussed, along with their suitability for deoxygenation, hydrogenation and $\mathrm{C}-\mathrm{C}$ coupling chemistry. This chemistry is necessary during pyrolysis vapor upgrading for improved bio-oil quality, which enables efficient downstream hydroprocessing; $\mathrm{C}-\mathrm{C}$ coupling helps increase the proportion of diesel/jet fuel range product. One potential benefit of fixed bed upgrading over fluidized bed upgrading is catalyst flexibility, providing greater control over chemistry and product composition. Since this study is based on future projections, the impacts of uncertainties in the underlying assumptions are quantified via sensitivity analysis. This analysis indicates that catalyst researchers should prioritize by: carbon efficiency $>$ catalyst cost $>$ catalyst lifetime, after initially testing for basic operational feasibility.

Keywords Ex situ catalytic fast pyrolysis - Biofuel . Process design - Techno-economic assessment - Fixed bed reactor - Vapor phase upgrading $\cdot$ Hot gas filter $\cdot$ Aspen Plus

\section{Introduction}

Fast pyrolysis of biomass at ca. $500{ }^{\circ} \mathrm{C}$ and short residence times (ca. $2 \mathrm{~s}$ ) produces high liquid yields (60-75\%) upon vapor condensation [1]. The liquid, also known as bio-oil or pyrolysis oil, primarily contains oxygenated organic compounds, including carboxylic acids, ketones, alcohols, 


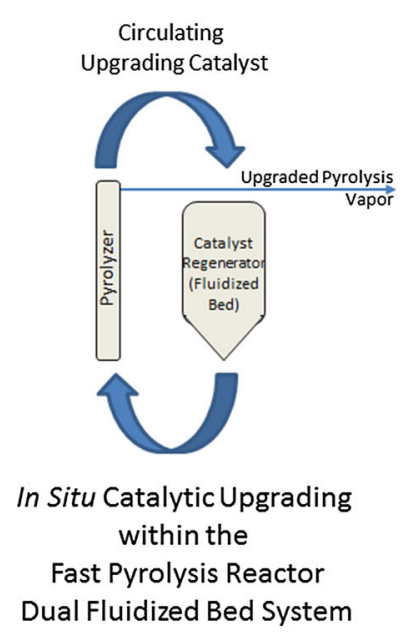

(a)

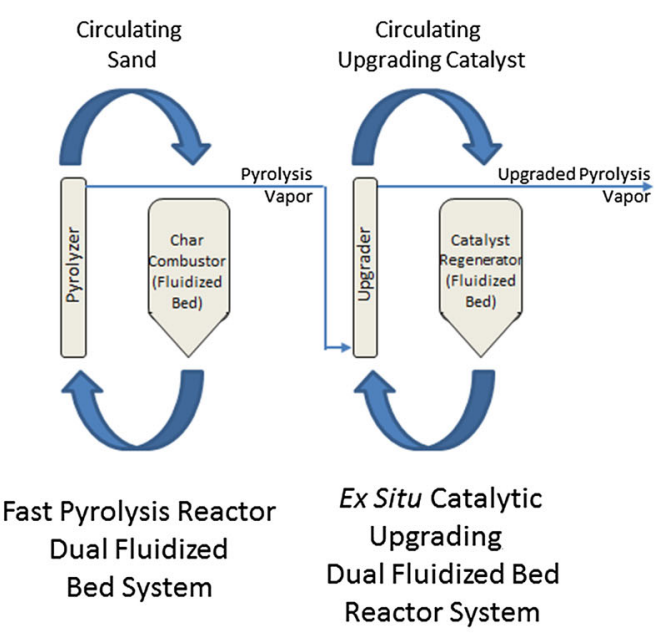

(b)

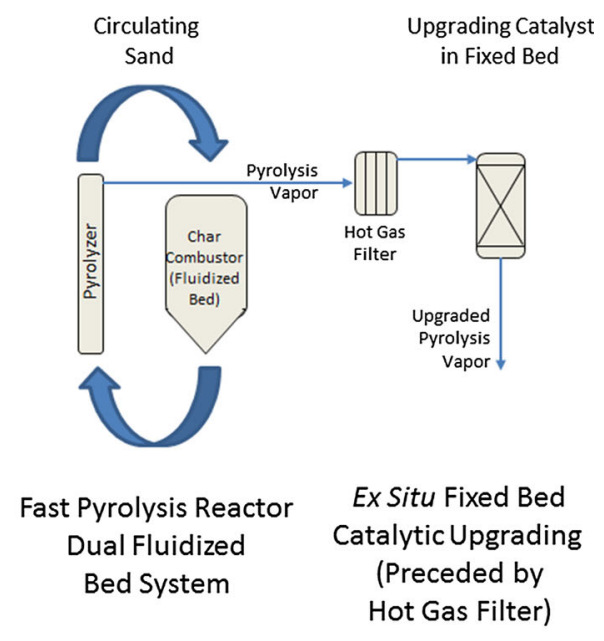

(c)

Fig. 1 Simplified illustration of biomass fast pyrolysis catalytic vapor upgrading reactor configurations: a in situ, b ex situ fluidized bed, and $\mathbf{c}$ ex situ fixed bed systems. Configurations $\mathbf{a}$ and $\mathbf{b}$ are detailed in [5]. Configuration $\mathbf{c}$ is the subject of this study

esters, aldehydes, furans, and phenolics, as well as a high concentration of water [2]. The production of hydrocarbon fuel blendstocks from the bio-oil entails deoxygenation and hydrogenation via high-pressure hydroprocessing of the bio-oil [3]. This downstream hydroprocessing is challenging compared to petroleum refinery operations because of the significant presence of reactive oxygenated species, which can lead to coking and difficulties during reactor operations [4]. Some of these difficulties can be alleviated by improving the quality (reducing oxygen and inherent chemical reactivity) through catalytic upgrading of the pyrolysis vapors prior to condensation. The key goals during catalytic upgrading are deoxygenation, minimization of carbon losses to coke and non-condensable gases, and hydrogenation. In addition, shifting the product slate towards the distillate-range (vs. gasoline-range) via $\mathrm{C}-\mathrm{C}$ coupling reactions is desirable for catering to heavy duty vehicles, and potentially aviation fuel. Thus, catalyst research and development will be key to achieve the desired chemical transformations in order to meet the above goals.

Potential process configurations for catalytic upgrading of pyrolysis vapors include (1) in situ, or within the fast pyrolysis reactor, and (2) ex situ, or in separate reactors after the removal of bulk solids including reactor bed material, char, and mineral matter. These process configurations were detailed in a recent design report led by the National Renewable Energy Laboratory (NREL) [5]. A circulating fluidized bed configuration, using metal-modified acidic zeolite (HZSM5) as the catalyst, was the basis for the ex situ vapor upgrading reactor in that study. Herein, we modified the prior conceptual design to develop a process model in Aspen Plus to investigate the potential use of fixed bed ex situ catalytic systems for fast pyrolysis vapor upgrading. The developed model also includes an upstream hot gas filter (HGF) to minimize fouling in the fixed bed systems. All three configurations are illustrated in a simplified diagram (Fig. 1).

One of the key reasons for exploring an ex situ fixed bed option is to expand the family of potential catalysts in order to achieve the desired chemistry. Fluidized systems are prone to catalyst attrition and losses. While modified methods of preparation can make catalysts more robust and less prone to attrition, it is impossible to eliminate it. Even small ongoing losses can lead to exorbitant costs when precious metals are used, thus negating their use in fluidized systems. This fixed bed study is able to include precious metal based catalysts. On the other hand, one of the primary advantages of a fluidized bed system is continuous and quick catalyst regeneration; in the absence of such a possibility, fixed bed catalyst design and operations are constrained by having to avoid conditions that lead to rapid catalyst deactivation, especially via coking.

The catalysts utilized in the fixed bed reactors were selected from recent literature reports; our methods for the calculation of catalyst costs are included in the supplementary material. The overall costs of the process, including minimum fuel selling price (MFSP), are determined and compared to the prior design report which used a circulating fluidized bed. A sensitivity analysis was performed to identify the effect of uncertainties on overall costs. The results from this work identify the trade-offs between circulating fluidized bed and fixed bed systems, provide guidance for selection of process operating conditions, highlight existing research gaps, and provide insight on catalyst development for ex situ upgrading. 


\section{Process Design and Techno-Economic Assessment}

\subsection{Conceptual Process Overview}

A simplified conceptual process flow diagram is shown in Fig. 2. The hot gas filter (HGF) and fixed bed reactors were added, replacing the fluidized bed system in the design report [5]. Detailed discussions for these additions are provided in following sections, including a discussion of catalyst options. Brief descriptions of the other process areas are included below; the interested reader can find further information in the detailed design report [5]. Process conditions are provided in Table 1 with further details in Table B1 in the supplementary material.

\subsubsection{Feedstock (Area 100)}

Blended feedstock with specifications similar to woody material is used in the model; the feed rate is 2000 dry metric tonnes per day. Specifications include $10 \mathrm{wt} \%$ moisture, $<1 \mathrm{wt} \%$ ash, and nominal size of $2 \mathrm{~mm}$. Further details can be found in a detailed report by the Idaho National Laboratory [6]. As mentioned in the design report [5], experimental verification of the performance of this feedstock in specific processes is a necessity.

\subsubsection{Fast Pyrolysis Reactor (in Area 200)}

A dual circulating fluidized bed system with an entrained flow fast pyrolysis reactor and a bubbling bed char combustor is used for fast pyrolysis. Heat is supplied to the endothermic fast pyrolysis reactions by hot sand from the char combustor. The fast pyrolysis reactor operates at $500{ }^{\circ} \mathrm{C}$ (outlet temperature), with short residence times $(<2 \mathrm{~s})$, at ca. 8 bar total pressure and in a hydrogen rich atmosphere $\left(71.5 \mathrm{~mol} \% \mathrm{H}_{2}\right.$, after accounting for incorporation of the $10 \mathrm{wt} \%$ moisture in wood into the vapor stream). The slightly elevated pressure along with the use of hydrogen is primarily designed to improve downstream catalytic vapor upgrading by enhancing the potential for hydrogen incorporation; the elevated pressure also helps reduce capital costs because of equipment volume reduction [5]. No reaction benefits from hydrogen are assumed

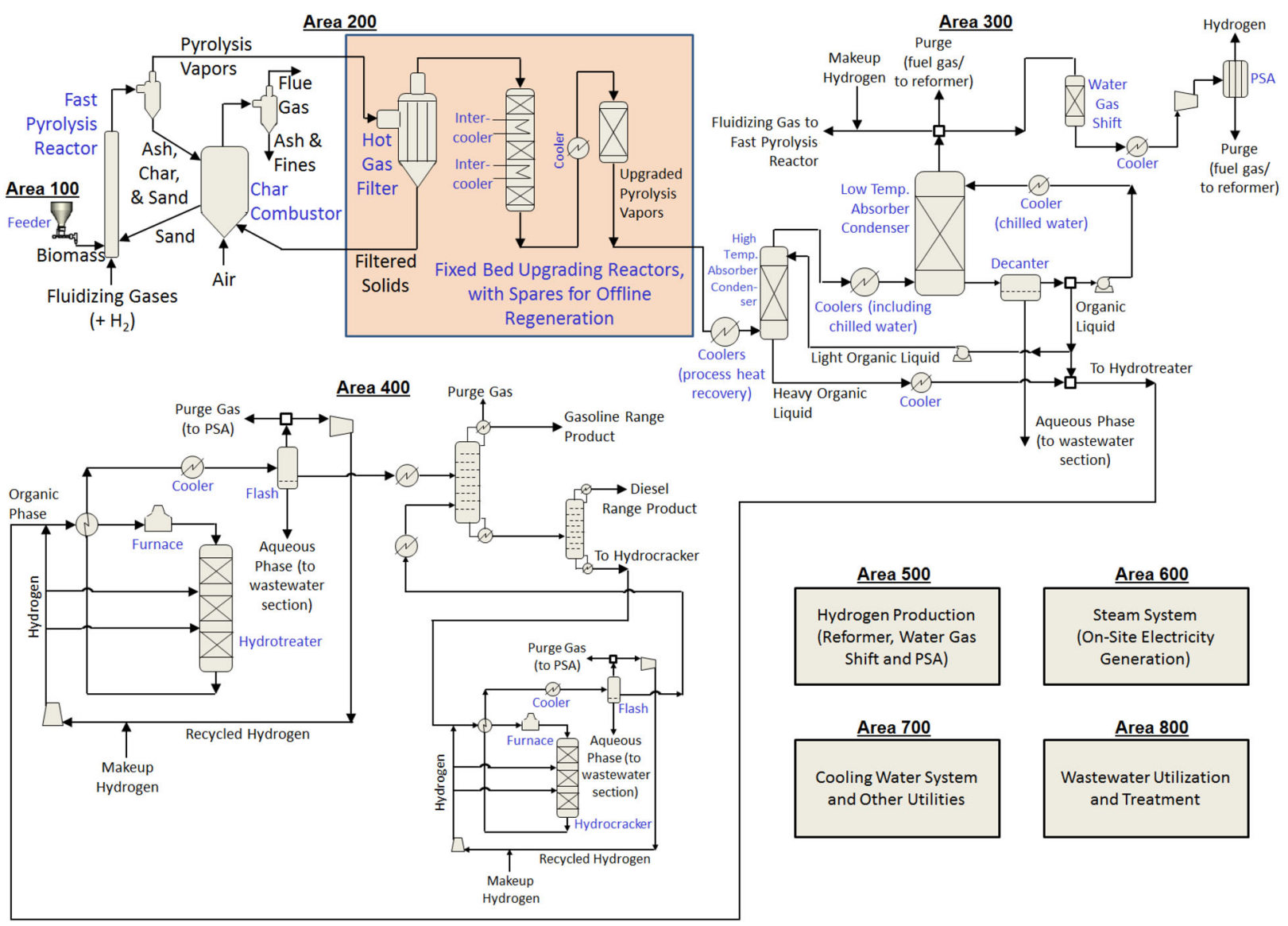

Fig. 2 Simplified process flow diagram with the hot gas filter and fixed bed ex situ pyrolysis vapor upgrading reactors highlighted (as the areas of focus in this study) 
Table 1 Overview of operating conditions (see Table B1 in supplementary material for further details)

\begin{tabular}{ll}
\hline Area 200: fast pyrolysis and vapor upgrading \\
\hline Fast pyrolysis reactor conditions & $500{ }^{\circ} \mathrm{C}, 8.3 \mathrm{bar}$ \\
Fluidized bed char combustor conditions & $720{ }^{\circ} \mathrm{C}, 8.1 \mathrm{bar}$ \\
Ex situ fixed bed upgrading reactors & \\
$\mathrm{H}_{2}$ concentration & $61 \mathrm{~mol} \%$ at inlet of \#1 \\
Reactor \#1 & \\
Operating pressure & $8.1 \mathrm{bar}$ \\
Inlet and outlet temp. & 350 and $400{ }^{\circ} \mathrm{C}$ \\
Reactor \#2 & 7.2 bar \\
Operating pressure & 275 and $293{ }^{\circ} \mathrm{C}$ \\
Inlet and outlet temp.
\end{tabular}

Area 300: vapor quench and condensation

Heavy fraction absorber-condenser

Overhead conditions

$178^{\circ} \mathrm{C}, 6.7$ bar

Light fraction absorber-condenser

Overhead conditions

$12{ }^{\circ} \mathrm{C}, 5.9$ bar

Area 400: hydroprocessing and product separation

Hydrotreater

$\begin{array}{ll}\text { Inlet and outlet temp. } & 375 \text { and } 403{ }^{\circ} \mathrm{C} \\ \text { Reactor inlet pressure } & 106.5 \mathrm{bar} \\ \text { Hydrocracker } & \\ \text { Inlet and outlet temp. } & 392 \text { and } 420^{\circ} \mathrm{C} \\ \text { Reactor inlet pressure } & 134.1 \mathrm{bar}\end{array}$

for the fast pyrolysis reactor; further experiments and research is necessary to understand the deviations from near atmospheric pressure operations (currently used as our basis for fast pyrolysis yields). The char combustor operates at $720{ }^{\circ} \mathrm{C}$, with $20 \%$ excess air; the heat of combustion is used to heat the circulating sand. Excess heat is used to generate steam for electricity production.

\subsubsection{Hot Gas Filter (HGF) (in Area 200)}

The HGF follows the fast pyrolysis reactor and is necessary to protect the downstream ex situ fixed bed reactors from entrained fine particles not removed by cyclones after the fast pyrolysis reactor. Further details are provided in Sect. 2.2.

\subsubsection{Ex Situ Fixed Bed Reactors (in Area 200)}

Two fixed bed reactor systems in series using different catalysts are included in the process model. The fast pyrolysis vapors are upgraded in these reactors. The reactor inlet temperatures are 350 and $275^{\circ} \mathrm{C}$ for the first and second reactors respectively, with corresponding temperature increases of 50 and $18{ }^{\circ} \mathrm{C}$ respectively. The hydrogen rich atmosphere is maintained from the introduction of hydrogen into the upstream fast pyrolysis reactor with ca. $60 \mathrm{~mol} \% \mathrm{H}_{2}$ in the vapor stream. The total pressure is approximately 8 bar. One spare reactor is provided in each of the two systems for offline catalyst regeneration. Further details are provided in Sects. 2.3 and 2.4 .

\subsubsection{Vapor Quench and Condensation (Area 300)}

The upgraded vapors from the ex situ reactor are cooled to its model-predicted dew point of $236{ }^{\circ} \mathrm{C}$ and then quenched in two absorber/condensers to avoid the potential fouling of heat exchangers by heavy organic products. The first absorber/condenser is used to condense the heavier organics. The vapors are then cooled by indirect heat exchange and then sent to a second absorber/condenser to recover light organics and water from non-condensable gases. The bulk (68\%) of the non-condensable gases is recycled to the fast pyrolysis reactor as fluidization gas; the recycle gas is supplemented with $\mathrm{H}_{2}$ in order to maintain $\mathrm{H}_{2}$ partial pressure in the fixed bed reactor. The remaining gases are used for hydrogen production via sour water gas shift, with hydrogen recovery using a pressure swing adsorption unit (PSA). The liquid from the second absorber/condenser separates into organic and aqueous phases. The aqueous phase is sent to wastewater treatment and the organic fraction is mixed with the heavy organic fraction and sent for hydroprocessing.

\subsubsection{Hydroprocessing and Product Separation (Area 400)}

The modeled oxygen content in the organic liquid sent for hydroprocessing is ca. $6 \%$. This area consists of a hydrotreater, a hydrocracker and two distillation columns. The purpose of the hydrotreater is to reduce the oxygen content to make products suitable for fuel blendstocks. The hydrotreated products are separated in the two distillation columns to gasoline and diesel range products. The heavier than diesel fraction is sent to the hydrocracker. The design assumptions for this section are the same as in the design report [5] with operations at ca. 105 bar, $375{ }^{\circ} \mathrm{C}$ (inlet) and $28{ }^{\circ} \mathrm{C}$ temperature rise in the hydrotreater, and ca. 135 bar, $392{ }^{\circ} \mathrm{C}$ (inlet) and $28{ }^{\circ} \mathrm{C}$ temperature rise in the hydrocracker. The hydrocracker products are sent back to the distillation columns for separation with the hydrotreated products.

\subsubsection{Hydrogen Production (Area 500)}

Hydrogen is produced from process off-gases in a steam reformer. A negligible amount of natural gas is introduced 
for model convergence and to leave the flexibility to introduce natural gas if necessary. The hydrogen demand can be met entirely using process gases, without any supplied natural gas.

\subsubsection{Heat, Power and Utilities (Areas 600 and 700)}

Process heat integration is an important aspect of thermochemical conversion processes. Hot and cold temperature vs. duty curves from process streams were created for pinch analysis in order to ensure that there were no temperature crossovers. The minimum approach temperature was ca. $11^{\circ} \mathrm{C}$. The cost of the heat exchange network was derived by scaling from the design report [5] using the total heat duty. A conventional steam cycle converts the excess heat into electricity for plant consumption and for sale of excess electricity to the grid. Excess heat is removed by air cooled exchangers above $60^{\circ} \mathrm{C}$, and a cooling water system is used primarily for cooling below $60{ }^{\circ} \mathrm{C}$. Cooling below $43{ }^{\circ} \mathrm{C}$ is achieved by using chilled water.

\subsubsection{Wastewater Management (Area 800)}

Wastewater produced primarily from the aqueous phase decanted after the second absorber/condenser is partially reused in compatible process streams after evaporation. The bulk of the aqueous phase hydrocarbons are combusted using a regenerative thermal oxidizer (RTO). Onsite wastewater treatment is used to handle other streams.

\subsection{Hot Gas Filter}

A hot gas filter is necessary to remove particulate matter upstream of the fixed bed vapor upgrading reactor systems. Physical protection from clogging and the removal of alkali containing mineral matter present in biomass can prevent catalyst deactivation that is not easily recoverable by inreactor regeneration protocols. In this context, catalysts used in the selective catalytic reduction of $\mathrm{NO}_{x}$ with $\mathrm{NH}_{3}$ are known to be deactivated by alkali, especially potassium, via the reduction in acid sites [7]. However, there are potential economic detriments of using hot gas filters, specifically, added capital cost and carbon losses via additional solids and light gases formed during the filtration process [8]. For the base case, we assume that ca. $10 \%$ of the carbon present in the biomass feedstock is lost in the HGF as solid carbonaceous matter (assumed to be the same composition as coke) and light non-condensable gases ( $\mathrm{CO}, \mathrm{CO}_{2}, \mathrm{CH}_{4}$, and $\mathrm{C}_{2} \mathrm{H}_{4}$ ) formed by cracking. A carbon loss assumption of $10 \%$ was made based on the range of losses reported in [8]. More accurate mass balances are necessary for reduced uncertainty; we show the impacts of the uncertainties via sensitivity analysis.
A budgetary estimate for the HGF was provided by the Pall Corporation. The estimate was scaled based on the actual gas flow rate into the filtration system, as predicted by the Aspen Plus model. The installed cost of the system was \$18MM. Operating at higher than ambient pressures (ca. 8 bar) helped to significantly reduce capital costs compared to operating at near atmospheric conditions, because of lower volumetric flow. The system has a ceramic candle filter element with automated blowback for solids collection and retrieval during continuous operations. A permanent porous filter cake is initially formed on the ceramic candle and has been shown to stabilize the filter media permeability and improve the overall removal efficiency of the filter element. The periodic blowback (reverse gas flow) dislodges the filtered solid carbonaceous matter from the outer surface and maintains a low pressure drop in the filter elements by avoiding clogging [8]. In our process design, the collected solids are routed back to the char combustor bed of the dual-bed fast pyrolysis reactor system for combustion of the filtered material. Note that the cost of the char combustor and associated equipment increased as a result of the added combustion load from the filtered material; installation factors were also increased to account for the integration of solids handling. A pressure drop of 0.14 bar was used in the process model, consistent with recommendations from the Pall Corporation [8].

Although not included in the current design, there is potential for the inclusion of catalysts within the hot gas filtration system [9]. This can potentially help save on fixed bed reactor equipment; however, further experiments are necessary before inclusion of such an assumption into the process model is warranted. Another potential area of capital savings will be the use of a single cyclone after the fast pyrolysis reactor, instead of two cyclones in the current assumption; the removal of one of the cyclones may actually be necessary to allow the buildup of a filtration cake.

\subsection{Reactor Design and Cost-Ex Situ Fixed Bed Upgrading Systems}

Two sets of fixed bed reactor systems in series with different catalyst functionalities are used (Fig. 3). The upstream reactor (Fixed Bed Reactor \#1) has a relatively large exotherm from initial upgrading and higher reactivity; this assumption may change in the future depending on the actual chemistry, thus causing a shift in the heat balance and removal requirements in the two reactors. Each of the 50-50-50 parallel units (50\% capacity each in 3 units) was therefore designed to hold three catalyst beds with internal-coil intercoolers. The duty from the internal intercooler coils was added to the process heat exchange network. The diameter of the reactor was computed using 


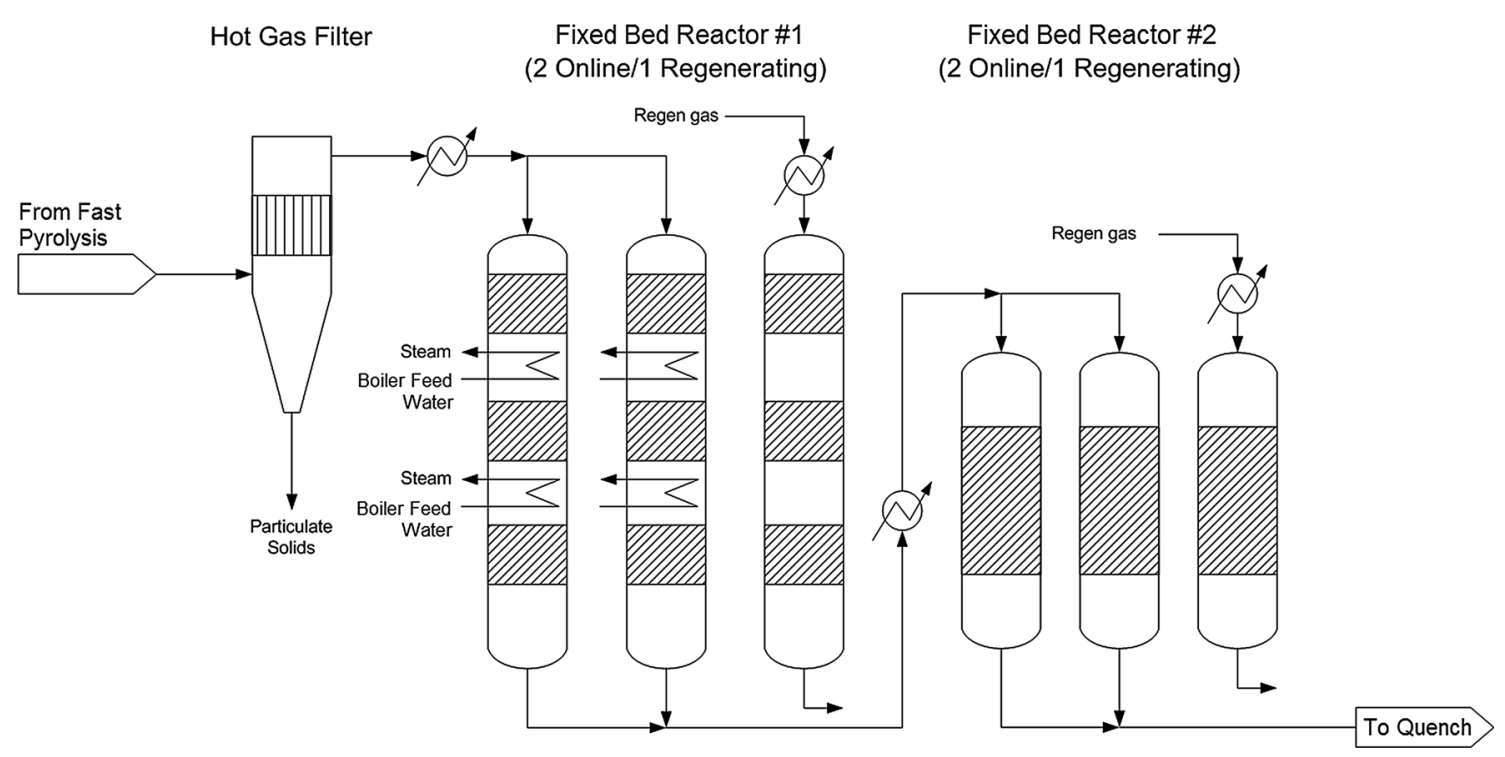

Fig. 3 Schematic of hot gas filter and ex situ fixed bed fast pyrolysis vapor upgrading reactors

the actual volumetric flow rate of the inlet gas $\left(\right.$ at $400{ }^{\circ} \mathrm{C}$ for design purposes) and a superficial velocity limit of $3 \mathrm{ft} /$ $\mathrm{s}$, taking into account a $4^{\prime \prime}$ refractory lining applied to the vessel interior. Note that one of the primary criteria for the choice of the superficial velocity was the pressure drop (sample calculations provided in [10]). The required catalyst volume was obtained by assuming a weight hourly space velocity (WHSV) of $5 \mathrm{~h}^{-1}$ (reactive species in the inlet pyrolysis vapor are relatively dilute, so the WHSV is less than $2 \mathrm{~h}^{-1}$ for the reactive condensable organic fraction), plus a $70 \%$ overdesign factor to account for catalyst deactivation over time. Due to the fact that the catalyst was divided into three beds per reactor and that the significant flow of nonreactive species largely controls the diameter of the reactor, design calculations result in catalyst beds that are shallow and prone to maldistributed gas flow [11]. The final bed length was therefore obtained by diluting the catalyst by $50 \%$ with inert bed support media such as ceramic balls, resulting in bed lengths of about $4^{\prime}$. The vessel length was then determined from the total length of the catalyst beds, assuming a $66 \%$ overall vessel void fraction to house the internals, including intercooler coils.

The downstream reactor, fixed bed reactor \#2, was modeled using the same general specifications for superficial velocity, WHSV, and overdesign, but as a single fixed bed without intercoolers. The catalyst was similarly diluted by $50 \%$ to ensure good flow distribution in the bed, and the overall vessel void fraction was reduced to $33 \%$, resulting in vessels with the same diameter as the upstream reactor, but shorter (without the intercoolers).

Cost estimates for the vessels were developed in Aspen Capital Cost Estimator, ACCE v8.4 (2013\$). Due to the corrosive nature of pyrolysis vapors, the costs were developed using carbon steel shells with $0.125^{\prime \prime}$ of Inconel cladding and $4^{\prime \prime}$ refractory lining. Extra manholes were specified for catalyst loading/unloading and a $60 \%$ allowance was added for Inconel-clad internals such as flow distributors, support rings, screens etc. (but not intercooler coils, which were assumed captured in the total capital for the heat exchange network, which is scaled from design report [5] using the process heat duty). Installation factors were also taken from ACCE, with $30 \%$ added as an allowance for regeneration piping. Table 2 summarizes the specifications and costs of the fixed bed vapor phase upgrading reactors.

\subsection{Reaction Chemistry and Catalyst Options}

The chemical transformations targeted during ex situ catalytic fast pyrolysis are hydrogenation, deoxygenation, and $\mathrm{C}-\mathrm{C}$ coupling [12]. Some examples of these reactions are shown in Table 4 (a more thorough description of these reactions can be found in [12]). The $\mathrm{H} / \mathrm{C}$ molar ratio for raw pyrolysis bio-oil ranges from 0.9 to 1.5 [13-15], thus hydrogen incorporation is required to produce finished fuels similar to gasoline, diesel, and jet fuel ( $\mathrm{H} / \mathrm{C}$ molar ratio of 1.9-2.2). However, hydrogenation reactions are generally exothermic and are therefore favored at lower temperatures. For example, the hydrogenation of the phenyl ring in catechol, phenol, and benzene (products derived from the pyrolysis of lignin) is thermodynamically unfavorable at temperatures above $300{ }^{\circ} \mathrm{C}$ [16]. Accordingly, the extent of hydrogen incorporation in these fixed bed systems will be limited by thermodynamic equilibrium, with greater hydrogen incorporation achieved in fixed bed reactor \#2 due to its lower operating temperature. The lower operating pressure 
Table 2 Fixed bed reactor design basis, capital and catalyst costs

\begin{tabular}{|c|c|c|c|}
\hline $\begin{array}{l}\text { Fixed bed vapor phase } \\
\text { upgrading }\end{array}$ & Unit & $\begin{array}{l}\# 1 \\
\text { (upstream) }\end{array}$ & $\begin{array}{l}\# 2 \\
(\text { downstream) }\end{array}$ \\
\hline $\begin{array}{l}\text { Reactors on stream } \\
\text { (parallel) }\end{array}$ & & 2 & 2 \\
\hline Spares & & 1 & 1 \\
\hline Design pressure & bar & 8.9 & 8.9 \\
\hline WHSV & $/ \mathrm{h}$ & 5.0 & 5.0 \\
\hline Bed length overdesign & & $70 \%$ & $70 \%$ \\
\hline Superficial velocity & $\mathrm{ft} / \mathrm{s}$ & 3 & 3 \\
\hline Vessel void fraction & $\%$ & $66 \%$ & $33 \%$ \\
\hline Refractory thickness & in & 4 & 4 \\
\hline Catalyst density & $\mathrm{lb} / \mathrm{ft}^{3}$ & 78 & 78 \\
\hline Catalyst inert volume & $\%$ & $50 \%$ & $50 \%$ \\
\hline Mass flow rate & $\mathrm{lb} / \mathrm{h}$ & 317,600 & 317,600 \\
\hline Volumetric flow rate & $\begin{array}{r}\text { actual } \\
\mathrm{ft}^{3} / \mathrm{h}\end{array}$ & $2,307,000$ & $2,307,000$ \\
\hline Diameter & $\mathrm{ft}$ & 12.5 & 12.5 \\
\hline Total catalyst on-stream & $\mathrm{lb}$ & 108,000 & 108,000 \\
\hline $\begin{array}{l}\text { Catalyst per on-stream } \\
\text { reactor }\end{array}$ & $\mathrm{lb}$ & 54,000 & 54,000 \\
\hline $\begin{array}{l}\text { Catalyst volume per } \\
\text { reactor }\end{array}$ & $\mathrm{ft}^{3}$ & 690 & 690 \\
\hline Bed height (incl. inerts) & $\mathrm{ft}$ & 12.6 & 12.6 \\
\hline Vessel height & $\mathrm{ft}$ & 37 & 37 \\
\hline Base cost & & $\$ 2,493,000$ & $\$ 1,600,000$ \\
\hline Install factor & & 1.32 & 1.47 \\
\hline Adder for regeneration & & 0.3 & 0.3 \\
\hline Total install factor & & 1.62 & 1.77 \\
\hline Total capital (2013\$) & & $\$ 12,106,000$ & $\$ 8,487,000$ \\
\hline Catalyst type $^{\mathrm{a}}$ & & $\begin{array}{l}\text { Non-precious } \\
\text { metal based }\end{array}$ & $\begin{array}{l}\text { Precious } \\
\text { metal based }\end{array}$ \\
\hline $\operatorname{Cost}^{\mathrm{a}}(/ \mathrm{lb})$ & & $\$ 12$ & $\$ 166$ \\
\hline Catalyst lifetime $^{\mathrm{a}}$ (years) & & 2 & 2 \\
\hline $\begin{array}{l}\text { Catalyst materials recovery } \\
\text { credit }\end{array}$ & & $0 \%$ & $65 \%$ \\
\hline $\begin{array}{l}\text { Catalyst load cost (for } \\
\text { online }+ \text { spare reactors) }\end{array}$ & & $\$ 2,317,700$ & $\$ 25,465,400$ \\
\hline
\end{tabular}

${ }^{a}$ Values used for cost calculations. Unit catalyst costs of $\$ 12 / \mathrm{lb}$ and $\$ 166 / \mathrm{lb}$ are averaged costs for non-precious and precious metal based catalysts respectively in Table 3. Actual materials and lifetimes will be based on experimental developments. Costs will change with metal loading assumptions. Impacts of cost variations and lifetimes are captured in sensitivity analysis

of the ex situ upgrading reactors, chosen to maintain the pyrolysis products in the vapor phase, will also limit the extent of hydrogenation, as compared to typical hydrotreating conditions (50-100 bar) [17, 18].

Deoxygenation can be achieved through decarbonylation (removal of oxygen as $\mathrm{CO}$ ), decarboxylation (removal of oxygen as $\mathrm{CO}_{2}$ ), hydrodeoxygenation (encompassing both direct hydrogenolysis and hydrogenation-dehydration; removal of oxygen as $\mathrm{H}_{2} \mathrm{O}$ ), and certain $\mathrm{C}-\mathrm{C}$ coupling reactions (discussed below) $[12,17,18]$. Decarbonylation and decarboxylation proceed through cleavage of $\mathrm{C}-\mathrm{C}$ bonds, thus reducing oxygen content at the expense of carbon efficiency, with decarboxylation being preferred as two oxygen atoms are removed per carbon atom. Hydrodeoxygenation proceeds through the cleavage of $\mathrm{C}-$ $\mathrm{O}$ bonds, but consumes at least one $\mathrm{H}_{2}$ molecule per oxygen atom. Based on a technoeconomic analysis of ex situ catalytic fast pyrolysis, carbon efficiency has a significant effect on the minimum fuel selling price, thus emphasis should be placed on reducing losses to coke and noncondensable gases (i.e., $\mathrm{CO}$ and $\mathrm{CO}_{2}$ ) [5]. Consequently, hydrodeoxygenation is the preferred deoxygenation route. The relative hydrodeoxygenation reactivity of various oxygenates present in biomass pyrolysis vapors is controlled, at least in part, by their $\mathrm{C}-\mathrm{O}$ bond dissociation energies $[4,17,19,20]$. Under typical hydrotreating conditions, aldehydes and ketones can be hydrogenated to alcohols below $200{ }^{\circ} \mathrm{C}$, aliphatic ethers and alcohols as well as carboxylic groups can be deoxygenated at 200-300 ${ }^{\circ} \mathrm{C}$, and phenolics and aromatic ethers can be deoxygenated at temperatures greater than $300{ }^{\circ} \mathrm{C}$ [4]. These temperature ranges likely shift slightly under ex situ catalytic upgrading conditions, but the trends should remain the same. Based on the literature insights, extensive deoxygenation is targeted in fixed bed reactor \#1; however, the degree of deoxygenation will need to be tightly controlled to allow for some oxygenates to pass through to reactor \#2 to participate in coupling reactions.

$\mathrm{C}-\mathrm{C}$ coupling under ex situ upgrading conditions can be achieved through methyl transfer (transalkylation), ketonization, aldol condensation, and hydroalkylation. The methyl transfer reaction facilitates carbon retention (i.e., carbon in a methyl group remains in the organic phase instead of leaving as methane), resulting in branched products with longer carbon chains. Acidic materials catalyze methyl transfer reactions at temperatures greater than $300{ }^{\circ} \mathrm{C}[21]$, indicating that this reaction will be prevalent in both fixed beds if a catalyst possessing acidic functionality is used. Ketonization couples two carboxylic acid molecules to produce a ketone, $\mathrm{CO}_{2}$, and $\mathrm{H}_{2} \mathrm{O}$ and is typically carried out at or above $350{ }^{\circ} \mathrm{C}$ over zeolites or acidic, basic, or amphoteric metal oxides [22, 23]. If ketonization is targeted in reactor \#1, then the resulting ketones can be coupled through aldol condensation reactions in reactor \#2. Aldol condensation couples two ketone or alcohol molecules to produce a heavier branched ketone, and is typically catalyzed by basic materials (e.g., metal oxides). Although aldol condensation reactions are typically carried out in the liquid phase [24, 25], recent work has demonstrated that these reactions can occur in the vapor phase at 
Table 3 Catalyst formulation, type, functionalities, and cost for the materials included in this process design for ex situ catalytic fast pyrolysis

\begin{tabular}{|c|c|c|c|c|c|c|c|c|}
\hline $\begin{array}{l}\text { Active } \\
\text { phase }\end{array}$ & Support & $\begin{array}{l}\text { Base case active } \\
\text { phase wt } \%^{\mathrm{a}}\end{array}$ & $\begin{array}{l}\text { Base case } \\
\text { catalyst cost } \\
(\$ / \mathrm{lb})\end{array}$ & $\begin{array}{l}\text { Active phase wt } \% \text { range } \\
\text { for sensitivity analysis }\end{array}$ & Catalyst type & $\begin{array}{l}\text { Catalytic } \\
\text { functionalities }\end{array}$ & $\begin{array}{l}\text { Fixed } \\
\text { bed }^{\text {b }}\end{array}$ & Refs. \\
\hline $\mathrm{Ru}$ & $\mathrm{TiO}_{2}$ & 5 & 115 & $2-10$ & $\begin{array}{l}\text { Noble metal/ } \\
\text { metal oxide }\end{array}$ & $\begin{array}{l}\text { Metallic, oxophilic } \\
\text { support }\end{array}$ & 1,2 & $\begin{array}{r}{[34-} \\
36]\end{array}$ \\
\hline $\mathrm{Pd}$ & $\mathrm{ZrO}_{2}$ & 2 & 205 & $0.5-5$ & $\begin{array}{l}\text { Noble metal/ } \\
\text { metal oxide }\end{array}$ & $\begin{array}{l}\text { Metallic, oxophilic } \\
\text { support }\end{array}$ & 1,2 & [37] \\
\hline $\mathrm{Pd}$ & $\mathrm{SiO}_{2}$ & 2 & 227 & $0.5-5$ & $\begin{array}{l}\text { Noble metal/ } \\
\text { metal oxide }\end{array}$ & $\begin{array}{l}\text { Metallic, } \\
\text { inert support }\end{array}$ & 1,2 & [37] \\
\hline $\mathrm{Pd}$ & $\mathrm{Al}_{2} \mathrm{O}_{3}$ & 2 & 227 & $0.5-5$ & $\begin{array}{l}\text { Nobel metal/ } \\
\text { metal oxide }\end{array}$ & $\begin{array}{l}\text { Metallic, acidic } \\
\text { support }\end{array}$ & 1,2 & [37] \\
\hline $\mathrm{Ni}$ & $\mathrm{TiO}_{2}$ & 20 & 10 & $5-30$ & $\begin{array}{l}\text { Base metal/ } \\
\text { metal oxide }\end{array}$ & $\begin{array}{l}\text { Metallic, oxophilic } \\
\text { support }\end{array}$ & 1 & [38] \\
\hline $\mathrm{Pd}$ & HBEA & 0.1 & 58 & $0.05-1$ & $\begin{array}{l}\text { Noble metal/ } \\
\text { zeolite }\end{array}$ & $\begin{array}{l}\text { Noble metal, acidic } \\
\text { support }\end{array}$ & 1,2 & [31] \\
\hline $\mathrm{Ni}$ & HZSM5 & 5 & 14 & $1-5$ & $\begin{array}{l}\text { Base metal/ } \\
\text { zeolite }\end{array}$ & $\begin{array}{l}\text { Metallic, acidic } \\
\text { support }\end{array}$ & 1,2 & $\begin{array}{l}{[39,} \\
40]\end{array}$ \\
\hline $\mathrm{Mo}_{2} \mathrm{C}$ & $\mathrm{SiO}_{2}$ & 10 & 16 & $10-20$ & $\begin{array}{l}\text { Metal carbide/ } \\
\text { metal oxide }\end{array}$ & $\begin{array}{l}\text { Bifunctional } \\
\text { (metallic and } \\
\text { acidic) }\end{array}$ & 1 & $\begin{array}{r}{[41-} \\
43]\end{array}$ \\
\hline $\mathrm{MoO}_{3}$ & $\mathrm{SiO}_{2}$ & 10 & 9 & $10-20$ & $\begin{array}{l}\text { Metal oxide/ } \\
\text { metal oxide }\end{array}$ & $\begin{array}{l}\text { Oxophilic (oxygen } \\
\text { vacancies) }\end{array}$ & 1 & $\begin{array}{l}{[44,} \\
45]\end{array}$ \\
\hline $\mathrm{Ni}_{2} \mathrm{P}$ & $\mathrm{SiO}_{2}$ & 10 & 9 & $5-30$ & $\begin{array}{l}\text { Metal } \\
\text { phosphide/ } \\
\text { metal oxide }\end{array}$ & $\begin{array}{l}\text { Bifunctional } \\
\text { (metallic and } \\
\text { acidic) }\end{array}$ & 1 & $\begin{array}{l}{[46,} \\
47]\end{array}$ \\
\hline
\end{tabular}

a Selected based on references listed in this table

b Indicates applicability of the catalysts to fixed bed reactors \#1 or \#2 in this process model

temperatures greater than $300{ }^{\circ} \mathrm{C}$ [26-29]. This approach combining upstream ketonization with downstream aldol condensation and hydrogenation-dehydration provides a promising route for converting carboxylic acids into diesel/jet fuel range products [22, 26-28]. Hydroalkylation involves ring-coupling of phenol with cyclohexanol or cyclohexene on Brønsted acidic materials, resulting in the formation of bi-cyclic or tri-cyclic oxygenates, that can then undergo subsequent hydrodeoxygenation [30-32]. While most of the work on hydroalkylation of biomassderived phenolics has been performed in the aqueous liquid phase [30, 32], ring coupling has been observed in the vapor phase at temperatures similar to the operating temperature of fixed bed reactor \#2 [33]. Accordingly, hydroalkylation will be targeted in reactor \#2.

Catalysts for ex situ upgrading of biomass pyrolysis vapors need to be able to achieve the desired transformations discussed above, while also being cost-effective and stable. Research is ongoing to develop catalysts that can perform these transformations under the process conditions outlined in this study. Accordingly, a number of excellent reviews have been published in the last 3-4 years discussing potential catalysts for biomass pyrolysis vapor upgrading, highlighting the key advantages and disadvantages of the different materials, and identifying reaction mechanisms [12, 17, 18, 48, 49]. As the scope of this work is to evaluate a process design for ex situ catalytic fast pyrolysis incorporating hot gas filtration and fixed bed systems, a thorough discussion of catalyst types and functionalities is not included; however, a few catalyst types/formulations are highlighted as they are explicitly considered in the process design (Table 3). These materials were selected because they (1) encompass a variety of different catalyst types (noble metals, base metals, zeolites, metal carbides, metal oxides, and metal phosphides) and functionalities (metallic, Brønsted and Lewis acidic, oxophilic), (2) exhibit promising performance for some or all of the chemical transformations of interest (see references in Table 3), and (3) span a large range of costs. Catalyst costs were estimated using a spreadsheet-based catalyst costing tool being developed at NREL (details regarding catalyst cost calculations are included in the supplementary material). Based on the catalyst functionalities described in the references in Table 3 and the aforementioned reviews, some of the catalysts $\left(\mathrm{Ni} / \mathrm{TiO}_{2}, \mathrm{Mo}_{2} \mathrm{C} / \mathrm{SiO}_{2}, \mathrm{MoO}_{3} / \mathrm{SiO}_{2}\right.$, and $\mathrm{Ni}_{2} \mathrm{P} / \mathrm{SiO}_{2}$ ) were only applicable to fixed bed reactor $\# 1$; all of the other materials were evaluated for their use in both fixed bed reactors \#1 and \#2. 
Table 4 Desirable reactions and potential catalysts

\begin{tabular}{|c|c|c|}
\hline Reaction types & Example reactions & Potential catalysts from Table 3 \\
\hline Hydrogenation & H & $\mathrm{Ru} / \mathrm{TiO}_{2}, \mathrm{Pd} / \mathrm{ZrO}_{2}, \mathrm{Pd} / \mathrm{SiO}_{2}, \mathrm{Pd} / \mathrm{Al}_{2} \mathrm{O}_{3}, \mathrm{Ni} / \mathrm{TiO}_{2}, \mathrm{Pd} / \mathrm{HBEA}, \mathrm{Ni} / \mathrm{HZSM} 5$ \\
\hline \multicolumn{3}{|l|}{ Deoxygenation } \\
\hline Decarbonylation & & Reaction type not desired because of carbon loss \\
\hline Decarboxylation & & Reaction type not desired because of carbon loss \\
\hline Hydrodeoxygenation & & $\mathrm{Ru} / \mathrm{TiO}_{2}, \mathrm{Pd} / \mathrm{ZrO}_{2}, \mathrm{Pd} / \mathrm{SiO}_{2}, \mathrm{Pd} / \mathrm{Al}_{2} \mathrm{O}_{3}, \mathrm{Ni} / \mathrm{TiO}_{2}, \mathrm{Pd} / \mathrm{HBEA}, \mathrm{Ni} / \mathrm{HZSM} 5$ \\
\hline $\begin{array}{l}\text { Direct } \\
\text { deoxygenation }\end{array}$ & & $\mathrm{Ru} / \mathrm{TiO}_{2}, \mathrm{Ni} / \mathrm{TiO}_{2}, \mathrm{Mo}_{2} \mathrm{C} / \mathrm{SiO}_{2}, \mathrm{MoO}_{3} / \mathrm{SiO}_{2}, \mathrm{Ni}_{2} \mathrm{P} / \mathrm{SiO}_{2}$ \\
\hline \multicolumn{3}{|l|}{$\mathrm{C}-\mathrm{C}$ coupling } \\
\hline Transalkylation & & $\mathrm{Pd} / \mathrm{Al}_{2} \mathrm{O}_{3}, \mathrm{Pd} / \mathrm{HBEA}, \mathrm{Ni} / \mathrm{HZSM} 5$ \\
\hline Ketonization & & $\mathrm{Ru} / \mathrm{TiO}_{2}, \mathrm{Ni} / \mathrm{TiO}_{2}, \mathrm{Pd} / \mathrm{HBEA}, \mathrm{Ni} / \mathrm{HZSM} 5$ \\
\hline Aldol condensation & $R_{1}$ & $\begin{array}{l}\mathrm{Pd} / \mathrm{ZrO}_{2}, \mathrm{Pd} / \mathrm{HBEA}, \\
\mathrm{Ni} / \mathrm{HZSM} 5\end{array}$ \\
\hline Hydroalkylation & & $\mathrm{Pd} / \mathrm{ZrO}_{2}, \mathrm{Pd} / \mathrm{Al}_{2} \mathrm{O}_{3}, \mathrm{Pd} / \mathrm{HBEA}$ \\
\hline
\end{tabular}

\subsection{Catalyst Maintenance and Metal Recovery}

Coke deposition on the ex situ upgrading catalyst will need to be limited for feasible fixed bed systems operations. To this end, lessons can be drawn from catalytic reforming systems in petroleum refining. Semi-regenerative systems with regeneration upon shutdown every 6-24 months, cyclic systems with spare reactors for more frequent online regeneration, and continuous regeneration systems have been used [50]. Cyclic operations are envisioned in our case through the inclusion of a spare reactor, with an additional installation factor of 0.3 (Table 2) to allow for regular regeneration. Allowable coke deposition before the necessity of regeneration is an important metric for process operation. During actual operations, this point is determined by a performance threshold; however, in the absence of experimental data, we have modeled the allowable coke deposition at $7 \mathrm{wt} \%$ of the catalyst, based on reports for catalytic reforming [51]. Considering the fixed bed reactor
\#1 design basis in Table 2, the weight of catalyst online is $108,000 \mathrm{lb}$, with an allowable coke deposit of $7560 \mathrm{lb}$ at the $7 \mathrm{wt} \%$ limit. Note that the distribution of carbon will not be uniformly $7 \mathrm{wt} \%$; more coke deposition is likely near the reactor inlet. A nominal coke deposition rate of $85 \mathrm{lb} / \mathrm{h}$ was assumed in the model, which allows for nearly 4 days of operations with two reactors, or approximately 2 days for the regeneration of catalyst in each reactor vessel. It will need to be determined whether this is an allowable coke deposition rate for continuous operations and whether additional spare reactors will be necessary. This process consideration provides guidance to researchers developing catalytic materials for fixed bed systems. Catalysts developed will need to minimize coke deposition and have effective regeneration protocols. Using low concentrations of oxygen (to limit temperature rise) is one of the common ways to eliminate coke via burn-off. Hydrogen-rich gases and stripping steam are among other regeneration agents. Specific in-reactor regeneration 
strategies need to be developed depending on the catalyst material [52].The impact of the frequency of catalyst regeneration on catalyst longevity also needs to be considered during catalyst development.

It is imperative to recover the precious metals for reuse from the spent catalyst. This is typically done by the catalyst vendors who take care of providing a fresh batch at a cost that accounts for metal recovery. Since our method for projecting catalyst costs uses a ground-up approach with materials and processing costs, it is important to discount the recovery of metals from the catalyst replacement cost. The economics of catalyst supply, with their costs and associated agreements, are closely guarded to maintain competitive advantages in the catalyst industry. A sample calculation in a brochure from TRICAT, Inc. [53] sheds some light on the cost of precious metals recovery, reporting a reclamation cost of $\$ 1.25 / \mathrm{lb}$, a preprocessing cost of $\$ 0.60 / \mathrm{lb}$ of catalyst, and a precious metal recovery of $>96 \%$. Reclamation costs need to be vetted for specific catalysts, and it is understood that reclamation processes will need to be specific to the catalyst type [54]. In our model, we assumed a $65 \%$ cost recovery for the precious metal catalyst used in fixed bed reactor \#2 and a no cost recovery for the low-cost catalyst in fixed bed reactor \#1. Based on the above information, along with a more conservative assumption of $\$ 3 / \mathrm{lb}$ reclamation cost, our cost calculations for an averaged precious metal based catalyst (average cost of precious metal based catalysts in Table 3 is $\$ 166 / \mathrm{lb}$ ) show that a $65 \%$ cost recovery from precious metal reclamation is easily feasible for a catalyst that costs $\$ 166 / \mathrm{lb}$ (our assumed base case catalyst cost for reactor \#2, see Table 2). The percent cost recovery from low-cost catalysts is dependent on the cost of the metal components, as shown specifically for a Ni-based catalyst [55]; we assume no cost recovery for the $\$ 12 / \mathrm{lb}$ (averaged unit catalyst cost as shown in Table 2) catalyst in reactor \#1. Impacts of uncertainties in this area are quantified later through a sensitivity analysis. Our assumption about catalyst refurbishing cost is also conservative relative to another study where it was assumed to be $10 \%$ of the total catalyst cost per year, albeit for a different catalyst [56].

\subsection{Process and Yield Assumptions}

The Aspen Plus simulation documented in the design report [5] for ex situ upgrading in a catalytic fluidized bed reactor was modified to include the hot gas filter and fixed bed reactor system discussed above. The set of model compounds in the simulation was kept the same, as were the physical property methods used: Peng Robinson-Boston Mathias (PR-BM) for the process and steam table correlations (STEAM-TA) for the steam cycle. The underlying process assumptions upstream and downstream of the pyrolysis vapor upgrading reactors were likewise consistent with the fluidized bed base case (see Table B1 in the supplementary material).

In the vapor upgrading section, the key difference between the fluidized and fixed bed upgrading reactors was the loss via coke production. As mentioned earlier, it was assumed to be an operational necessity that the fixed bed reactor should have significantly lower coke formation than the ex situ fluidized bed reactor. This was offset, however, by carbon losses to non-condensable gases and solid carbonaceous matter (assumed same composition as coke) in the hot gas filter. The key process performance metrics for the fixed bed process are listed in Table 5 and compared with the fluidized bed processes. Note the slightly lower coke or solid carbonaceous matter in the fixed bed case was offset (as a design choice) by higher gas phase losses, to maintain similar organic liquid yields. Similar yields and reactor conversions were assumed primarily to allow a direct comparison of the economics of the two ex situ configurations by maintaining process parity among the other (non-Area 200) areas; consequently the overall products and carbon efficiencies for the two processes are quite similar. The differences between the ex situ fluidized and fixed bed configurations with respect to achievable product slates will be captured in future work as the chemistry and accessible pathways are confirmed through catalyst research and development, and verified in operating systems.

In the fluidized bed case, the heat released by combustion of deposited coke on the catalyst was recovered to the plant steam loop. Removing the fluidized bed reactor and catalyst regenerator for the fixed bed case therefore caused a shift in the heat balance. Solid carbonaceous matter generated and captured in the HGF was routed to the fast pyrolysis char combustor for burning with heat recovery, but the fixed bed reactors were assumed to be regenerated offline without heat recovery (from the smaller amount of carbon deposited in the fixed bed). A pinch analysis was conducted to verify that there would be no temperature crossovers in the heat integration as a result of this change, but a detailed heat exchange network was not created. The total capital cost for process heat exchangers was scaled by total duty from the heat exchanger capital in the design report ex situ case [5].

\subsection{Economic Assumptions and the Minimum Fuel Selling Price (MFSP)}

Mature nth-plant economics were assumed for projecting the cost of products; this is a set of assumptions reflecting a successful future in which several plants using the same technology have been built and are operating. Inflated project costs associated with risk financing, longer start-ups, equipment overdesign, and other costs are therefore ignored 
Table 5 Process metrics for ex situ fluidized bed (2022 Target) [5] and fixed bed model in this study with similar yield assumptions

\begin{tabular}{|c|c|c|}
\hline & $\begin{array}{l}\text { Fluidized bed } \\
\text { [5] }\end{array}$ & $\begin{array}{l}\text { Fixed bed (this } \\
\text { study) }\end{array}$ \\
\hline \multicolumn{3}{|l|}{ Fast pyrolysis intermediate } \\
\hline Gas species- $\mathrm{CO}, \mathrm{CO}_{2}, \mathrm{C}_{1}-\mathrm{C}_{4}$ (wt $\%$ of dry biomass) & 13 & 13 \\
\hline Organics (wt $\%$ of dry biomass) & 64 & 64 \\
\hline Water (wt\% of dry biomass) & 11 & 11 \\
\hline Char (wt\% of dry biomass) & 12 & 12 \\
\hline \multicolumn{3}{|l|}{ Vapor upgrading product } \\
\hline Gas (wt $\%$ of dry biomass) & 23 & 26 \\
\hline Aqueous phase (wt $\%$ of dry biomass) & 30 & 30 \\
\hline Carbon loss (\% of $\mathrm{C}$ in biomass) & 1.3 & 1.3 \\
\hline Organic phase (wt $\%$ of dry biomass) & 27 & 27 \\
\hline $\mathrm{H} / \mathrm{C}$ molar ratio & 1.6 & 1.5 \\
\hline Oxygen (wt $\%$ in organic phase) & 6.4 & 6.1 \\
\hline Carbon efficiency $(\%)$ & 44 & 44 \\
\hline Solid losses, char + coke (wt $\%$ of dry biomass) & $12+8$ & $12+5$ \\
\hline \multicolumn{3}{|l|}{ Final fuel blendstock } \\
\hline Yield (\%, w/w dry biomass) & 25 & 24 \\
\hline $\begin{array}{l}\text { Hydroprocessing carbon efficiency (\%, not including light } \\
\text { dissolved gases in feed and product; assumed efficiency } \\
\text { scaling by } \mathrm{O} \text { content in organic liquid feed-higher efficiency } \\
\text { for lower O) }\end{array}$ & 94 & 94 \\
\hline Overall carbon efficiency ( $\%$ of $\mathrm{C}$ in biomass) & 41.5 & 41.5 \\
\hline Overall carbon efficiency ( $\%$ of $\mathrm{C}$ in biomass $+\mathrm{NG}$ ) & 41.5 & 41.4 \\
\hline Total product (GGE/dry U.S. ton) & 78 & 77 \\
\hline Gasoline-range product (gallons/dry U.S. ton) & 36 & 36 \\
\hline Diesel-range product (gallons/dry U.S. ton) & 39 & 38 \\
\hline Gasoline/diesel-range product (\% GGE basis) & $45 / 55$ & $46 / 54$ \\
\hline Oxygen content in cumulative product (wt $\%$ ) & 0.4 & 0.4 \\
\hline \multicolumn{3}{|l|}{ Natural gas and electricity } \\
\hline Natural gas energy input (\% of biomass, LHV basis) & 0.2 & 0.2 \\
\hline Natural gas cost contribution ( $\phi / \mathrm{GGE})$ & 0.2 & 0.3 \\
\hline Surplus electricity credit ( $\phi / \mathrm{GGE})$ & 3 & 3 \\
\hline \multicolumn{3}{|l|}{ Fuel blendstock production efficiencies (various bases) } \\
\hline Biomass feedstock (\%, LHV basis) & 57 & 56 \\
\hline Biomass + natural gas $(\%$, LHV basis) & 57 & 56 \\
\hline $\begin{array}{l}\text { Biomass + natural gas + electricity ( } \%, \text { LHV basis, all } \\
\text { electrical energy converted to heat) }\end{array}$ & 57 & 57 \\
\hline
\end{tabular}

in order to focus on quantifying the real economic impact of research. Some of the important assumptions are listed in Table 6, with further details in the prior design report [5].

Using a comprehensive list of mechanical equipment in the plant, bare equipment costs are computed; these are derived from various sources including vendors, engineering consultants, and ACCE. The total installed cost (TIC) is then obtained by applying installation factors to the bare equipment costs. Variable operating costs are calculated based on materials and energy use; fixed operating costs are based on expenditures such as plant maintenance and personnel. The minimum fuel selling price
(MFSP) is determined by a discounted cash flow analysis, which accounts for capital cost payments, depreciation, product sales, and operating costs [5].

\section{Results and Discussion}

\subsection{Process Economics}

Table 7 presents a summary of the TIC for each area of the plant and compares the fixed bed upgrading case to the fluidized bed case in [5]. Note that the feedstock and 
Table 6 Summary of nth-plant techno-economic assumptions [5]

\begin{tabular}{ll}
\hline Economic parameters & Assumed basis \\
\hline Cost basis year & 2011 \\
Debt/equity for plant financing & $60 / 40 \%$ \\
Internal rate of return (after-tax) for equity financing & $10 \%$ \\
Interest rate and term for debt financing & $8.0 \%$ annually/10 years \\
Total income tax rate & $35 \%$ \\
Plant life & 30 years \\
Plant depreciation schedule & 7 -year MACRS \\
Steam plant depreciation & 20 -year MACRS \\
Plant salvage value & No value \\
Construction period & 3.0 years \\
Fixed capital expenditure schedule & $8 \%$ in year 1, 60 \% in year 2, 32 \% in year 3 \\
Start-up time & 6 months \\
Revenues during start-up & $50 \%$ of normal operation \\
Variable costs during start-up & $75 \%$ of normal operation \\
Fixed costs during start-up & $100 \%$ of normal operation \\
On-stream percentage after start-up & $90 \%$ (7884 operating hours per year) \\
\hline
\end{tabular}

MACRS modified accelerated cost recovery system defined by the US Internal Revenue Service

\begin{tabular}{llll}
\hline & & \multicolumn{2}{l}{ TIC (MM\$) } \\
\cline { 3 - 4 } Area & Process description & Fluidized bed [5] & Fixed bed (this study) \\
\hline 100 & Feed handling and drying ${ }^{\mathrm{a}}$ & 0.4 & 0.4 \\
200 & Fast pyrolysis & 76.8 & 101.2 \\
& Hot gas filter & - & 18.1 \\
& Vapor upgrading & 50.2 & 25.2 \\
300 & Pyrolysis vapor quench and product recovery & 24.2 & 23.5 \\
400 & Hydroprocessing and product separation & 29.1 & 30.0 \\
500 & Hydrogen plant & 66.8 & 75.8 \\
600 & Steam system and power generation & 47.9 & 50.6 \\
700 & Cooling water and other utilities & 9.3 & 9.4 \\
800 & Wastewater management and recycle & 12.9 & 13.2 \\
ISBL (areas 100-400) & 180.7 & 198.4 \\
OSBL (areas 500-800) & 136.8 & 149.0 \\
Total & & 317.5 & 347.4 \\
Total capital investment (TCI) &
\end{tabular}

${ }^{a}$ Most investment costs for feed handling and drying are included in the per-unit woody feedstock price. This cost is for a secondary biomass dryer that serves to preheat the feed

b See Table B2 in the supplementary material for details of indirect factors and other calculations used to calculate the TCI handling costs are lumped in an \$80/dry US ton feedstock cost, based on an Idaho National Laboratory report [6]. In the pyrolysis area, lower capital costs for the less complex fixed bed upgrading reactor are mostly offset by the addition of the hot gas filter. Upstream of the upgrading reactor, the fast pyrolysis reactor system is more expensive for fixed-bed upgrading, even though the process specifications are similar; the bulk of this difference is due to the larger char combustor and associated equipment (including the sand cooler) required to burn the additional solid carbonaceous matter formed and rejected in the hot gas filter. The installed cost for the fast pyrolysis system increased from \$77MM [5] to \$101MM. The difference in the cost of hydrogen plant is also noticeable; this difference arises from a higher hydrogen demand in the fixed bed case. Even though the organic liquid yield after vapor condensation is 
Table 8 Operating cost summary

\begin{tabular}{llllll}
\hline Category & \multicolumn{2}{l}{ Fluidized bed [5] } & & \multicolumn{2}{l}{ Fixed bed (this study) } \\
\cline { 2 - 3 } & Cents/GGE & $\$ /$ Year & & Cents/GGE & $\$ /$ Year \\
\hline Feedstock & 102.6 & $\$ 57,940,000$ & & 103.6 & $\$ 57,940,000$ \\
Natural gas & 0.2 & $\$ 100,000$ & & 0.3 & $\$ 200,000$ \\
Catalysts & 36.2 & $\$ 20,430,000$ & & 16.2 & $\$ 9,030,000$ \\
Sand & 0.5 & $\$ 300,000$ & & 0.5 & $\$ 300,000$ \\
Other raw materials & 1.1 & $\$ 610,000$ & & 1.1 & $\$ 640,000$ \\
Waste disposal & 1.7 & $\$ 930,000$ & & 1.7 & $\$ 940,000$ \\
Purchased electricity & - & $\$ 0$ & & & $\$ 0$ \\
Fixed costs & 47.7 & $\$ 26,950,000$ & & 51.7 & $\$ 28,910,000$ \\
Electricity co-product credit & $(2.6)$ & $-\$ 1,480,000$ & & $(3.3)$ & $-\$ 1,830,000$ \\
Capital depreciation & 49.7 & $\$ 28,080,000$ & & 54.9 & $\$ 30,730,000$ \\
Average income tax & 19.8 & $\$ 11,200,000$ & & 22.2 & $\$ 12,430,000$ \\
Average return on investment & 74.6 & $\$ 42,150,000$ & & 84.2 & $\$ 47,110,000$ \\
\hline
\end{tabular}

similar in the two cases, there is higher gas and lower coke produced in the fixed bed case (see Table 5). The higher gas production dilutes the off-gases. In order to maintain a similar partial pressure of hydrogen at the upgrading reactor inlet it is necessary to add more hydrogen in the fixed bed case; this is to make up for the added dilution of the recycled off-gases used for fast pyrolysis reactor fluidization. Installed capital costs for the other areas are similar for the two cases.

Table 7 also shows the total capital investment (TCI) and Table B2 in the supplementary material presents more details of the derivation of the TCI for the two processes. The TCI is obtained from the installed capital costs, escalated by expected direct and indirect capital costs associated with construction, engineering, and project management services. Table 8 compares the variable and fixed operating costs for fluidized and fixed bed systems. On a unit mass basis, the fixed bed upgrading reactor uses more expensive catalyst than the fluidized bed. When expressed as an operating cost, however, catalyst costs for the fixed bed are significantly lower than the fluidized bed, because the fixed bed does not require constant catalyst replacement. For the fixed bed upgrading case, the MFSP is $\$ 3.33 / \mathrm{GGE}$, compared to $\$ 3.31 / \mathrm{GGE}$ for the fluidized bed case [5]. Figure 4 presents the contributions of individual process areas toward the MFSP.
Fig. 4 Cost contribution by process areas

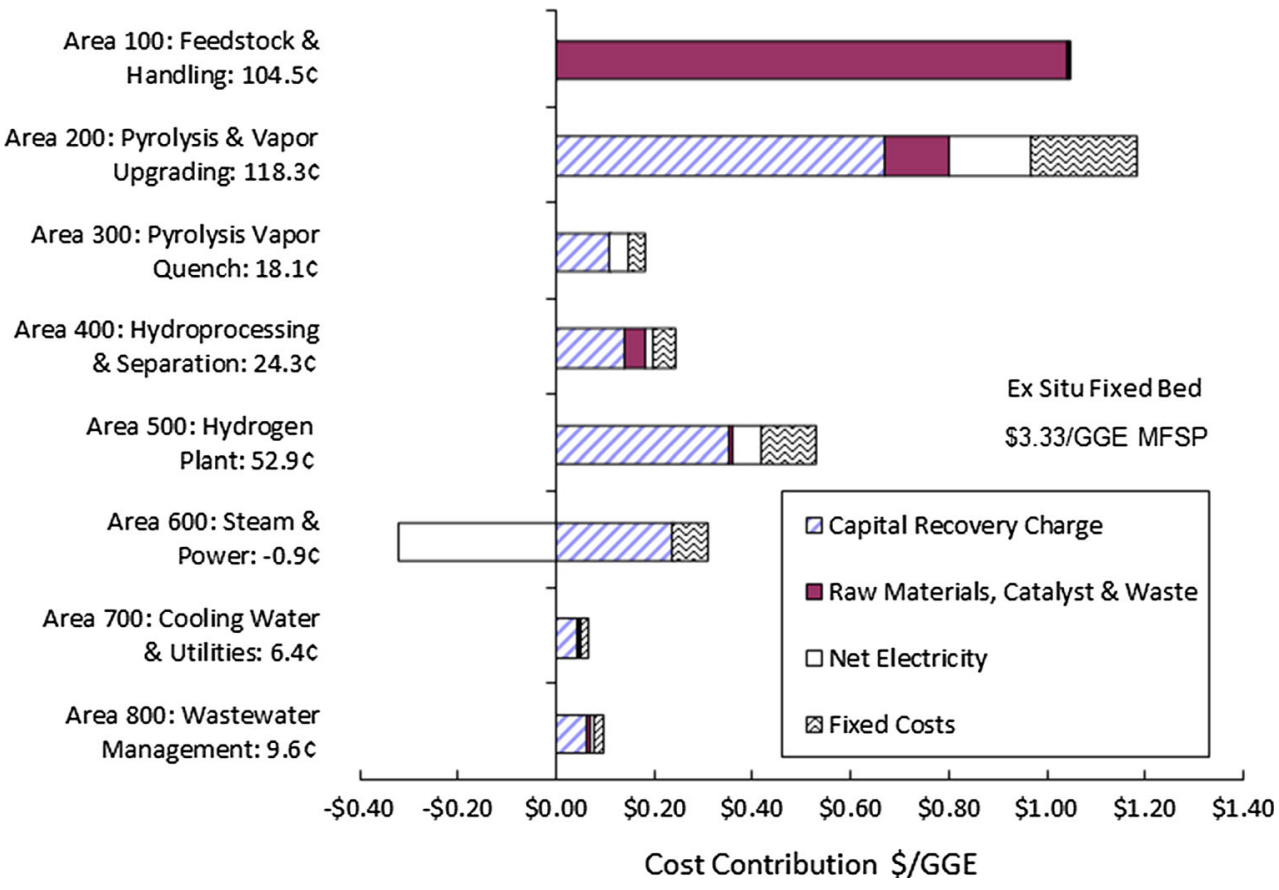




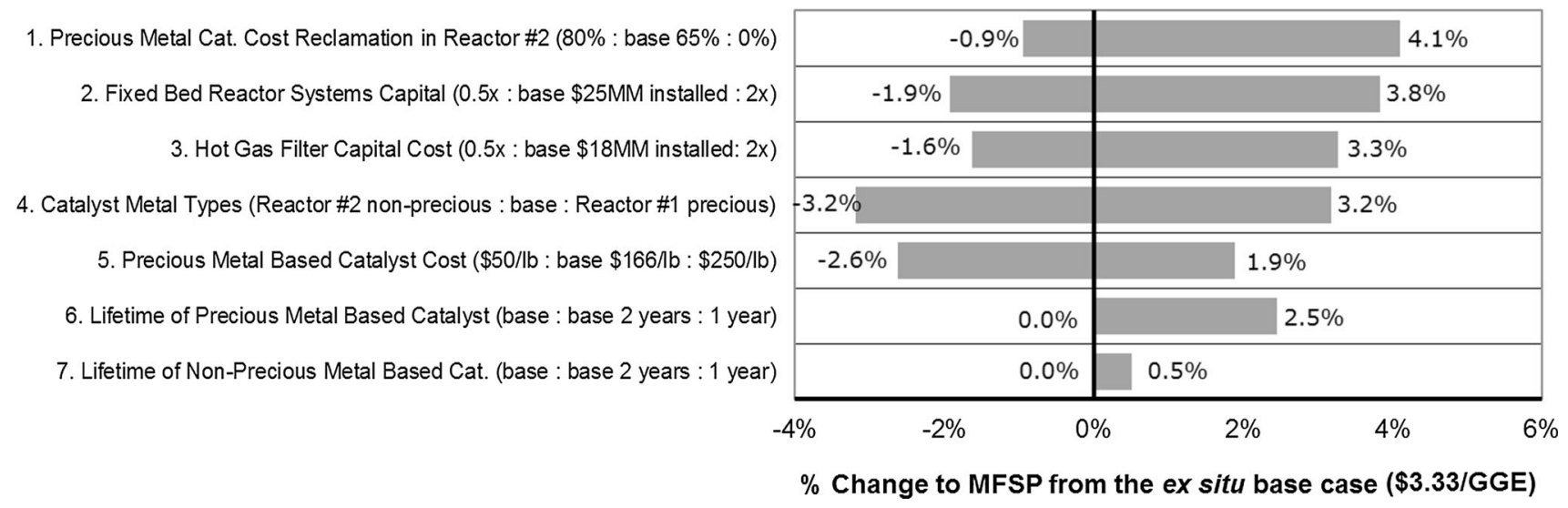

Fig. 5 Sensitivity analysis for HGF and fixed bed reactors

\subsection{Sensitivity Analysis and Discussion}

The base case economic results presented in the previous section depend on financial, process design, and performance assumptions. This study outlines a possible pathway to future feasibility, and it is imperative that significant research needs to happen to approach the described base case scenario. The impacts of deviations from some of the key assumptions are presented here, along with a discussion of other implications of this conceptual process analysis.

This study only evaluated sensitivity cases dealing with the hot gas filter and fixed bed systems; all other sensitivities for the process are captured in the previous design report [5] and remain relatively unchanged. Figure 5 presents sensitivity scenarios surrounding the hot gas filter and fixed bed systems; the results are presented as percent deviations from the base case MFSP of $\$ 3.33 / \mathrm{GGE}$ (Fig. 4), with case numbers on the far left of each item on the y-axis. Case 1 in Fig. 5 shows the impact of the percentage of the bulk catalyst cost that can be recovered in the metals reclamation process. As previously discussed, there is a possibility of higher cost recovery than the assumed $65 \%$ in our base case, especially when the cost of metals is the predominant cost component. This parameter is usually well established for commercial catalyst vendors, but not made widely known in order to protect their commercial interests. Case 2 is relevant for capturing variations in cost based on reactor design and configuration assumptions, e.g., smaller reactor volumes because of higher WHSV, the requirement for more spare reactors for regeneration because of quicker deactivation or longer regeneration times compared to our base case, higher installation costs because of complex regeneration protocols or potential addition of elaborate safety precautions during the regeneration of specific catalysts etc. Case 3 shows the impact of HGF capital; in this context it may be possible to take an integrated look at this system during future development, with possible elimination of one of the two cyclones after the fast pyrolysis reactor, or the potential elimination of one of the fixed bed reactor systems by being able to include catalysts within the HGF filter elements [9]. There can be significant cost reductions by switching to lower cost catalysts by either lowering or eliminating the use of precious metals (case 4) or increasing catalyst lifetimes (case 6). As is expected, increasing catalyst lifetimes of higher cost catalysts has a larger economic benefit compared to increasing the lifetime of lower cost catalysts (case 6 vs case 7) based on our current assumptions regarding used catalyst cost recovery, although there may be other implications if there are frequent shutdowns even when operating with low cost catalysts; reactors need to be adequately configured to avoid operational disruptions. It should be noted that reactor \#1 will be exposed to more reactive vapors and will likely require quicker catalyst replacement compared to reactor $\# 2$, and the 1 year lifetime assumed in sensitivity case 7 is relevant. This also suggests that using a precious metal based catalyst in reactor \#1 (case 4), along with a lower 1-year lifetime (case 6) will have significant negative economic impacts.

In addition to Fig. 5, it is important to reiterate from the design report [5] that carbon efficiency (or hydrocarbon yield) has one of the biggest impacts on the MFSP; a $5 \%$ increase in carbon efficiency can lower the MFSP by ca. $8 \%$; consequently lower carbon efficiency can have a significant negative economic impact. This point is relevant for the fixed bed vapor upgrading system both with respect to the HGF and the fixed bed reactors. The importance of having accurate experimental mass balances and strategies for loss minimization in the HGF is thus highlighted. This analysis also indicates that with respect to the vapor upgrading catalyst development, researchers should prioritize by: carbon efficiency $>$ catalyst 
cost $>$ catalyst lifetime (assuming lifetimes up to 1 year can be reached).

Yields may also be affected by feedstock choices and formulations, as fast pyrolysis yields and quality (including oxygen content) depend significantly on the feedstock, and particularly the types and amounts of mineral matter [57]. Typically, the higher carbon and lower ash content in woody feedstocks leads to higher organic liquid yields after fast pyrolysis, ultimately leading to higher hydrocarbon product yields. In this respect, it can be pointed out that while lower feedstock carbon content or carbon losses to the solid phase cannot be compensated for during vapor upgrading, it may be possible to recover some of the condensable fragmented oxygenated species as larger, liquid fuel-range molecules via $\mathrm{C}-\mathrm{C}$ coupling discussed in this article; it is important to experimentally study specific large-volume feedstocks of interest in order develop optimal conversion strategies.

\section{Conclusion}

This study presented a conceptual process design and techno-economic assessment for production of hydrocarbon fuel blendstock from biomass by fast pyrolysis followed by ex situ catalytic vapor-phase upgrading. A fixed bed upgrading reactor system with a hot gas filter was proposed and compared to the fluidized bed upgrading system detailed in a recent design report led by NREL [5]. The target yield assumptions were similar by design, but with some key tradeoffs such as low carbon losses to coke during upgrading, and increased losses to non-condensable gases and carbonaceous solids in the hot gas filter. Overall, the fuel blendstock yields and carbon efficiencies were very similar for the two designs. This led to a fairly direct comparison highlighting a small number of specific differences in capital and operating costs associated with a fixed bed versus a fluidized bed reactor, as well as the impact of introducing a hot gas filter to protect the fixed bed system from entrained fine particulate matter.

Total capital costs for the fixed bed system with hot gas filter are higher than for the fluidized bed reactor system. Although the fixed bed reactor itself is actually less expensive than the fluidized bed, this is offset by the cost of the hot gas filter. A significant cost increase is attributed to the upstream fast pyrolysis reactor, which requires a larger char combustor and associated equipment to burn the solid carbonaceous matter from the hot gas filter. Higher capital costs of the fixed bed system are offset by lower catalyst costs. Overall the fixed bed reactors in our design use more expensive catalyst, but do not require constant catalyst replacement, as is necessary in the fluidized bed system. The projected production costs are comparable for the two ex situ upgrading alternatives, with MFSPs of $\$ 3.33 / \mathrm{GGE}$ and $\$ 3.31 / \mathrm{GGE}$ for the fixed and fluidized bed systems, respectively.

One key potential benefit of fixed bed upgrading over fluidized bed upgrading is catalyst flexibility. The ability to control the chemistry and the upgraded product slate can yield significant benefits downstream. Beyond improved ability to deoxygenate, hydrogenate, and perform $\mathrm{C}-\mathrm{C}$ coupling, further development of fixed bed catalytic upgrading systems must also focus on minimizing coke formation and yield losses associated with cracking. Regeneration studies will also be critical for continuous operations. Effective reclamation of precious metals will ensure precious-metal catalyst costs can be controlled. Most experimental campaigns and catalyst selection studies to-date have been carried out on a limited number of model compounds. The challenges of transitioning from these model compounds to real pyrolysis vapors should not be underestimated, and success will depend on effective handling of these challenges. With the maturity in catalyst research, it will be imperative to tailor catalysts, processes, and operations to better optimize for major bulk-supply feedstocks, like the present day optimization for feedstock changes in petroleum refineries.

Acknowledgments This work was supported by the U.S. Department of Energy under Contract No. DE-AC36-08GO28308 with the National Renewable Energy Laboratory. Funding provided by U.S. DOE Office of Energy Efficiency and Renewable Energy Bioenergy Technologies Office. We thank the Pall Corporation for providing information about the hot gas filter, and Michael Talmadge and other NREL Thermochemical Platform research staff for their inputs.

The U.S. Government retains and the publisher, by accepting the article for publication, acknowledges that the U.S. Government retains a nonexclusive, paid-up, irrevocable, worldwide license to publish or reproduce the published form of this work, or allow others to do so, for U.S. Government purposes.

Open Access This article is distributed under the terms of the Creative Commons Attribution 4.0 International License (http://crea tivecommons.org/licenses/by/4.0/), which permits unrestricted use, distribution, and reproduction in any medium, provided you give appropriate credit to the original author(s) and the source, provide a link to the Creative Commons license, and indicate if changes were made.

\section{References}

1. Mohan D, Pittman CU, Steele PH (2006) Pyrolysis of wood/ biomass for bio-oil: a critical review. Energy Fuels 20:848-889

2. Bridgewater A, Czernik S, Diebold J, Meier D, Oasmaa A, Peacocke C, Piskorz J, Radlein D (1999) Fast pyrolysis of biomass: a handbook. CPL Press, West Berkshire

3. Jones S, Meyer P, Snowden-Swan L, Padmaperuma A, Tan E, Dutta A, Jacobson J, Cafferty K (2013) Process design and economics for the conversion of lignocellulosic biomass to hydrocarbon fuels: fast pyrolysis and hydrotreating bio-oil 
pathway. NREL/TP-5100-61178; PNNL-23053. National Renewable Energy Laboratory, Pacific Northwest National Laboratory, Golden

4. Elliott DC (2007) Historical developments in hydroprocessing bio-oils. Energy Fuels 21:1792-1815

5. Dutta A, Sahir A, Tan E, Humbird D, Snowden-Swan L, Meyer P, Ross J, Sexton D, Yap R, Lukas J (2015) Process design and economics for the conversion of lignocellulosic biomass to hydrocarbon fuels-thermochemical research pathways with in situ and ex situ upgrading of fast pyrolysis vapors. NREL/TP5100-62455, PNNL-23823

6. Jacobson JJ, Cafferty K, Roni MS, Lamers P, Kenney K (2014) Feedstock and conversion supply system design and analysisthe feedstock logistics design case. INL/EXT-14-33227. Idaho Falls, Idaho National Laboratory

7. Peng Y, Li J, Chen L, Chen J, Han J, Zhang H, Han W (2012) Alkali metal poisoning of a $\mathrm{CeO}_{2}-\mathrm{WO}_{3}$ catalyst used in the selective catalytic reduction of NOx with $\mathrm{NH} 3$ : an experimental and theoretical study. Environ Sci Technol 46:2864-2869

8. Baldwin RM, Feik CJ (2013) Bio-oil stabilization and upgrading by hot gas filtration. Energy Fuels 27(6):3224-3238

9. Nacken M, Mab L, Heidenreich S, Baron GV (2009) Performance of a catalytically activated ceramic hot gas filter for catalytic tar removal from biomass gasification gas. Appl Catal B 88:292-298

10. Froment GF, Bischoff KB, Wilde JD (2011) Chemical reactor analysis and design, 3rd edn. Wiley, New York

11. Porter KE, Ali QH, Hassan AO, Aryan AF (1993) Gas distribution in shallow packed beds. Ind Eng Chem Res 32:2408-2417

12. Ruddy DA, Schaidle JA, Ferrell JR, Wang J, Moens L, Hensley JE (2014) Recent advances in heterogeneous catalysts for bio-oil upgrading via "ex situ catalytic fast pyrolysis": catalyst development through the study of model compounds. Green Chem $16: 454$

13. Maggi R, Delmon B (1994) Characterization and upgrading of bio-oils produced by rapid thermal processing. Biomass Bioenergy 7:245

14. Bridgwater AV (2012) Review of fast pyrolysis of biomass and product upgrading. Biomass Bioenergy 38:68

15. Choudhary TV, Phillips CB (2011) Renewable fuels via catalytic hydrodeoxygenation. Appl Catal A 397:1

16. Lu J, Behtash S, Mamun O, Heyden A (2015) Theoretical investigation of the reaction mechanism of the guaiacol hydrogenation over a Pt(111) catalyst. ACS Catal 5:2423

17. Wang H, Male J, Wang Y (2013) Recent advances in hydrotreating of pyrolysis bio-oil and its oxygen-containing model compounds. ACS Catal 3:1047

18. Saidi M, Samimi F, Karimipourfard D, Nimmanwudipong T, Gates BC, Rahimpour MR (2014) Upgrading of lignin-derived bio-oils by catalytic hydrodeoxygenation. Energy Environ Sci $7: 103$

19. Grange P, Laurent E, Maggi R, Centeno A, Delmon B (1996) Hydrotreatment of pyrolysis oils from biomass: reactivity of the various categories of oxygenated compounds and preliminary techno-economical study. Catal Today 29:297

20. Furimsky E (2000) Catalytic hydrodeoxygenation. Appl Catal A 199:147

21. Tsai T-C, Liu S-B, Wang I (1999) Disproportionation and transalkylation of alkylbenzenes over zeolite catalysts. Appl Catal A 181:355

22. Iliopoulou EF (2010) Review of C-C coupling reactions in biomass exploitation processes. Curr Org Synth 7:587

23. Pham TN, Sooknoi T, Crossley SP, Resasco DE (2013) Ketonization of carboxylic acids: mechanisms, catalysts, and implications for biomass conversion. ACS Catal 3:2456

24. Nikolopoulos AA, Jang BWL, Spivey JJ (2005) Acetone condensation and selective hydrogenation to MIBK on Pd and Pt hydrotalcite-derived $\mathrm{Mg}-\mathrm{Al}$ mixed oxide catalysts. Appl Catal A 296:128

25. Chen YZ, Liaw BJ, Tan HR, Shen KL (2001) One-step synthesis of methyl isobutyl ketone from acetone and hydrogen over $\mathrm{Pd} /$ $\left(\mathrm{Nb}_{2} \mathrm{O}_{5} / \mathrm{SiO}_{2}\right)$ catalysts. Appl Catal A 205:61

26. Kunkes EL, Gürbüz EI, Dumesic JA (2009) Vapour-phase C-C coupling reactions of biomass-derived oxygenates over $\mathrm{Pd} /$ $\mathrm{CeZrO}_{\mathrm{x}}$ catalysts. J Catal 266:236

27. Gurbuz EI, Kunkes EL, Dumesic JA (2010) Dual-bed catalyst system for $\mathrm{C}-\mathrm{C}$ coupling of biomass-derived oxygenated hydrocarbons to fuel-grade compounds. Green Chem 12:223

28. Crisci AJ, Dou H, Prasomsri T, Román-Leshkov Y (2014) Cascade reactions for the continuous and selective production of isobutene from bioderived acetic acid over zinc-zirconia catalysts. ACS Catal 4:4196

29. Rodrigues ACC, Monteiro JLF (2001) Use of bifunctional metal/ base catalyts in the direct synthesis of MIBK from acetone: comparison between Pt and Pd catalysts. In: van Steen E, Claeys M, Callanan LH (eds.) Studies in surface science and catalysis, vol 154, Part C. Elsevier, p 2395

30. Hong D-Y, Miller SJ, Agrawal PK, Jones CW (2010) Hydrodeoxygenation and coupling of aqueous phenolics over bifunctional zeolite-supported metal catalysts. Chem Commun 46:1038

31. Zhao C, Camaioni DM, Lercher JA (2012) Selective catalytic hydroalkylation and deoxygenation of substituted phenols to bicycloalkanes. J Catal 288:92

32. Zhao C, Song W, Lercher JA (2012) Aqueous phase hydroalkylation and hydrodeoxygenation of phenol by dual functional catalysts comprised of Pd/C and H/La-BEA. ACS Catal 2:2714

33. Nimmanwudipong T, Runnebaum R, Tay K, Block D, Gates B (2011) Cyclohexanone conversion catalyzed by $\mathrm{Pt} / \mathrm{C}-\mathrm{Al}_{2} \mathrm{O}_{3}$ : evidence of oxygen removal and coupling reactions. Catal Lett 141:1072

34. Wan S, Pham T, Zhang S, Lobban L, Resasco D, Mallinson R (2013) Direct catalytic upgrading of biomass pyrolysis vapors by a dual function $\mathrm{Ru} / \mathrm{TiO}_{2}$ catalyst. AIChE J 59:2275

35. Boonyasuwat S, Omotoso T, Resasco D, Crossley S (2013) Conversion of guaiacol over supported Ru catalysts. Catal Lett 143:783

36. Pham T, Shi D, Resasco D (2014) Kinetics and mechanism of ketonization of acetic acid on $\mathrm{Ru} / \mathrm{TiO}_{2}$ catalyst. Top Catal 57:706

37. de Souza PM, Rabelo-Neto RC, Borges LEP, Jacobs G, Davis BH, Sooknoi T, Resasco DE, Noronha FB (2015) Role of keto intermediates in the hydrodeoxygenation of phenol over Pd on oxophilic supports. ACS Catal 5:1318

38. Yang Y, Ochoa-Hernández C, de la Peña O'Shea VA, Pizarro P, Coronado JM, Serrano DP (2014) Effect of metal-support interaction on the selective hydrodeoxygenation of anisole to aromatics over Ni-based catalysts. Appl Catal B 145:91

39. Vichaphund S, Aht-ong D, Sricharoenchaikul V, Atong D (2014) Catalytic upgrading pyrolysis vapors of Jatropha waste using metal promoted ZSM-5 catalysts: an analytical PY-GC/MS. Renew Energy 65:70

40. Iliopoulou EF, Stefanidis SD, Kalogiannis KG, Delimitis A, Lappas AA, Triantafyllidis KS (2012) Catalytic upgrading of biomass pyrolysis vapors using transition metal-modified ZSM-5 zeolite. Appl Catal B 127:281

41. Lee W-S, Wang Z, Zheng W, Vlachos DG, Bhan A (2014) Vapor phase hydrodeoxygenation of furfural to 2-methylfuran on molybdenum carbide catalysts. Catal Sci Technol 4:2340

42. Ren H, Yu W, Salciccioli M, Chen Y, Huang Y, Xiong K, Vlachos DG, Chen JG (2013) Selective hydrodeoxygenation of biomass-derived oxygenates to unsaturated hydrocarbons using molybdenum carbide catalysts. ChemSusChem 6:798 
43. Lee W-S, Wang Z, Wu RJ, Bhan A (2014) Selective vapor-phase hydrodeoxygenation of anisole to benzene on molybdenum carbide catalysts. J Catal 319:44

44. Prasomsri T, Nimmanwudipong T, Roman-Leshkov Y (2013) Effective hydrodeoxygenation of biomass-derived oxygenates into unsaturated hydrocarbons by $\mathrm{MoO}_{3}$ using low $\mathrm{H}_{2}$ pressures. Energy Environ Sci 6:1732

45. Prasomsri T, Shetty M, Murugappan K, Roman-Leshkov Y (2014) Insights into the catalytic activity and surface modification of $\mathrm{MoO}_{3}$ during the hydrodeoxygenation of lignin-derived model compounds into aromatic hydrocarbons under low hydrogen pressures. Energy Environ Sci 7:2660

46. Zhao HY, Li D, Bui P, Oyama ST (2011) Hydrodeoxygenation of guaiacol as model compound for pyrolysis oil on transition metal phosphide hydroprocessing catalysts. Appl Catal A 391:305

47. Bui P, Cecilia JA, Oyama ST, Takagaki A, Infantes-Molina A, Zhao H, Li D, Rodríguez-Castellón E, Jiménez López A (2012) Studies of the synthesis of transition metal phosphides and their activity in the hydrodeoxygenation of a biofuel model compound. J Catal 294:184

48. Wan S, Wang Y (2014) A review on ex situ catalytic fast pyrolysis of biomass. Front Chem Sci Eng 8:280

49. He Z, Wang X (2012) Hydrodeoxygenation of model compounds and catalytic systems for pyrolysis bio-oils upgrading. In: Catalysis for sustainable energy, vol 1, p 28
50. Rahimpour MR, Jafari M, Iranshahi D (2013) Progress in catalytic naphtha reforming process: a review. Appl Energy 109:79-93

51. Antos GJ, Aitani AM (2004) Catalytic naphtha reforming, revised and expanded, 2nd edn. CRC Press, New York

52. Bartholomew CH, Farrauto RJ (2005) Fundamentals of industrial catalytic processes, 2nd edn. Wiley, Hoboken

53. TRICAT, Inc. Brochure: Reasons to regenerate catalysts before metals reclamation. http://www.tricatgroup.com/pdf/ti-prereclaimburn-rationale.pdf

54. Dong H, Zhao J, Chen J, Wu Y, Li B (2015) Recovery of platinum group metals from spent catalysts: a review. Int J Miner Process. doi:10.1016/j.minpro.2015.06.009

55. Yang QZ, Qi GJ, Low HC, Song B (2011) Sustainable recovery of nickel from spent hydrogenation catalyst: economics, emissions and wastes assessment. J Clean Prod 19:365-375

56. Bond JQ et al (2014) Production of renewable jet fuel range alkanes and commodity chemicals from integrated catalytic processing of biomass. Environ Sci 7:1500

57. Howe D, Westover T, Carpenter D, Santosa D, Emerson R, Deutch S, Starace A, Kutnyakov I, Lukins C (2015) Field-to-fuel performance testing of lignocellulosic feedstocks: an integrated study of the fast pyrolysis-hydrotreating pathway. Energy Fuels 29:3188-3197 